\title{
Ubiquity and dominance of oxygenated species in organic aerosols in anthropogenically-influenced Northern Hemisphere midlatitudes
}

\author{
Q. Zhang, ${ }^{1}$ J. L. Jimenez, ${ }^{2}$ M. R. Canagaratna,${ }^{3}$ J. D. Allan, ${ }^{4}$ H. Coe, ${ }^{4}$ I. Ulbrich,${ }^{2}$ \\ M. R. Alfarra, ${ }^{5}$ A. Takami, ${ }^{6}$ A. M. Middlebrook, ${ }^{7}$ Y. L. Sun, ${ }^{1}$ K. Dzepina, ${ }^{2}$ E. Dunlea, ${ }^{2}$ \\ K. Docherty, ${ }^{2}$ P. F. DeCarlo, ${ }^{2}$ D. Salcedo, ${ }^{8}$ T. Onasch, ${ }^{3}$ J. T. Jayne, ${ }^{3}$ T. Miyoshi, ${ }^{6}$ \\ A. Shimono, ${ }^{9}$ S. Hatakeyama, ${ }^{6}$ N. Takegawa, ${ }^{10}$ Y. Kondo, ${ }^{10}$ J. Schneider, ${ }^{11}$ F. Drewnick, ${ }^{11}$ \\ S. Borrmann, ${ }^{11}$ S. Weimer, ${ }^{1}$ K. Demerjian, ${ }^{1}$ P. Williams, ${ }^{4}$ K. Bower, ${ }^{4}$ R. Bahreini, ${ }^{2,7}$ \\ L. Cottrell, ${ }^{12}$ R. J. Griffin, ${ }^{12}$ J. Rautiainen, ${ }^{13}$ J. Y. Sun, ${ }^{14}$ Y. M. Zhang, ${ }^{14}$ \\ and D. R. Worsnop ${ }^{3}$
}

Received 12 March 2007; revised 24 April 2007; accepted 25 May 2007; published 7 July 2007.

[1] Organic aerosol (OA) data acquired by the Aerosol Mass Spectrometer (AMS) in 37 field campaigns were deconvolved into hydrocarbon-like $\mathrm{OA}(\mathrm{HOA})$ and several types of oxygenated OA (OOA) components. HOA has been linked to primary combustion emissions (mainly from fossil fuel) and other primary sources such as meat cooking. OOA is ubiquitous in various atmospheric environments, on average accounting for $64 \%, 83 \%$ and $95 \%$ of the total OA in urban, urban downwind, and rural/remote sites, respectively. A case study analysis of a rural site shows that the OOA concentration is much greater than the advected HOA, indicating that HOA oxidation is not an important source of OOA, and that OOA increases are mainly due to SOA. Most global models lack an explicit representation of SOA which may lead to significant biases in the magnitude, spatial and temporal distributions of OA, and in aerosol hygroscopic properties. Citation: Zhang, Q., et al. (2007), Ubiquity and dominance of oxygenated species in organic aerosols in anthropogenically-influenced Northern Hemisphere midlatitudes, Geophys. Res. Lett., 34, L13801, doi:10.1029/2007GL029979.

\section{Introduction}

[2] Submicron aerosols have important effects on regional to global climate, visibility, human health, and ecological integrity. Organic species represent a significant and sometimes major (20-90\%) mass fraction of the submicron aerosol [Kanakidou et al., 2005]. Quantification and characterization of the sources and properties of submicron

\footnotetext{
${ }^{1}$ Atmospheric Sciences Research Center, University at Albany, State University of New York, New York, USA.

${ }^{2}$ Cooperative Institute of Research in Environment Sciences and Department of Chemistry and Biochemistry, University of Colorado, Boulder, Colorado, USA.

${ }^{3}$ Aerodyne Research Inc., Billerica, Massachusetts, USA.

${ }^{4}$ School of Earth, Atmospheric and Environmental Science, University of Manchester, Manchester, UK.

${ }^{5}$ Laboratory for Atmospheric Chemistry, Paul Scherrer Institute, Villigen, Switzerland.

${ }^{6}$ Chemical Reaction Section, Atmospheric Environment Division, National Institute for Environmental Studies, Tsukuba, Japan.

${ }^{7}$ Chemical Sciences Division, NOAA Earth System Research Laboratory, Boulder, Colorado, USA.

Copyright 2007 by the American Geophysical Union. 0094-8276/07/2007GL029979
}

organic aerosols $(\mathrm{OA})$ have been hampered by analytical difficulties [Turpin et al., 2000; Kanakidou et al., 2005], in particular the discrepancies between different thermal-optical organic carbon (OC) quantification and artifact removal techniques, and the minor fraction $(\sim 10 \%)$ of the OA mass that can typically be speciated by conventional techniques such as GC-MS [e.g., Schauer et al., 1996]. Several new methods can be used to gain quantitative data on the types of OA present [Fuzzi et al., 2001; Russell, 2003; Zhang et al., 2005a, 2005b]. The review by Kanakidou et al. [2005] outlined the homogenization of OA observations and the improvement of the characterization of OA composition and aging as two major research priorities.

[3] Recent results have shown that secondary organic aerosols (SOA), formed by chemical transformation and condensation of volatile and semivolatile species, are underestimated by an order of magnitude or more by current models when applied in and downwind of urban areas/ polluted regions [Volkamer et al., 2006, and references therein]. Updated budgets of organic species in the atmosphere also suggest underestimation of SOA [Goldstein and Galbally, 2007]. Also primary organic aerosol (POA) formed by fossil fuel combustion can be overestimated by the elemental carbon (EC) tracer data analysis technique due to the difficulty of estimating a representative OC/EC ratio for primary emissions from ambient measurements [Zhang et al., 2005a]. Most of these recent findings have resulted from the application of the Aerosol Mass Spectrometer (AMS) [Jayne et al., 2000; Jimenez et al., 2003; Allan et $a l ., 2004]$ that can determine quantitatively OA with high time and size resolution. The custom principal component analysis (CPCA) technique developed by Zhang et al. [2005a, 2005b] has enabled the separate quantification of

\footnotetext{
${ }^{8}$ Centro de Investigaciones Quimicas, Universidad Autónoma del Estado de Morelos, Cuernavaca, Mexico.

${ }^{9}$ Sanyu Plant Service Co., Ltd., Sagamihara, Japan.

${ }^{10}$ Research Center for Advanced Science and Technology, University of Tokyo, Tokyo, Japan.

${ }^{11}$ Department of Particle Chemistry, Max Planck Institute for Chemistry, Mainz, Germany.

${ }^{12}$ Climate Change Research Center, University of New Hampshire, Durham, New Hampshire, USA.

${ }^{13}$ Department of Physics, University of Kuopio, Kuopio, Finland.

${ }^{14}$ Center for Atmosphere Watch and Services, Chinese Academy of Meteorological Sciences, Beijing, China.
} 
several types of OA from AMS mass spectra into hydrocarbon-like organic aerosol (HOA), which in urban areas shows correspondence with fossil fuel POA and potentially include other primary sources such as meat cooking, and oxygenated organic aerosol (OOA).

[4] In several ambient case studies OOA has shown direct correspondence with SOA [Zhang et al., 2005a; de Gouw et al., 2005; Volkamer et al., 2006; Takegawa et al., 2006; Johnson et al., 2006] although in some cases OOA may also include contributions from biomass burning OA (BBOA) [Salcedo et al., 2006; M. R. Canagaratna et al., Identification of organic aerosol sources in Houston during the TEXAQS 2000 air quality study, manuscript in preparation, 2007, hereinafter referred to as Canagaratna et al., manuscript in preparation, 2007]. SOA produced in the laboratory has resulted in a range of OOA spectra [Bahreini et al., 2005; Alfarra et al., 2006], but recent results with SOA formed from diluted diesel exhaust yield a spectrum very similar to the most common ambient OOA [Robinson et al., 2007]. OOA was also found to strongly correlate with water-soluble OC in Tokyo [Kondo et al., 2007], which had been linked to SOA in a previous study [Sullivan et al., 2004]. Lanz et al. [2007] have recently applied the positive matrix factorization (PMF) model to an urban dataset in Zurich, Switzerland, and concluded that two types of OOA contribute about $2 / 3$ of the submicron OA mass, with the rest accounted by primary sources (mainly combustion and cooking).

[5] In this paper we apply an expanded version of the CPCA - a multiple component analysis (MCA) techniqueto 37 multiple week-long datasets obtained during different seasons at surface sites in 11 urban areas, 5 regions downwind of urban areas, and $11 \mathrm{rural} /$ remote locations in the Northern Hemisphere midlatitudes. The MCA method, which uses a different algorithm to solve the same mathematical problem as the PMF technique applied by Lanz et al. [2007], derives multiple components, including several OOA components that show different fragmentation patterns and oxygen to carbon ratios in their mass spectra. The MCA results are in general agreement with results from PMF [Ulbrich et al., 2006; Canagaratna et al., manuscript in preparation, 2007]. We interpret the results in terms of the importance of different sources and processes for the organic aerosol in these regions, and compare to the representation of OA in current global models.

\section{Methods}

[6] The AMS and its quantification of OA have been described in detail elsewhere [Canagaratna et al., 2007, and references therein]. The list of locations, times, and previous publications (almost all reporting only total OA, and not HOA/OOA) for each of these studies are given in Figure 1 and in the auxiliary material. ${ }^{1}$ OA spectra were analyzed with the MCA method, modified from that of Zhang et al. [2005b] to allow the identification of more than two components [Zhang et al., 2006]. The time series of mass concentrations and the mass spectra of the components were obtained and classified as HOA, several types of OOA, and

${ }^{1}$ Auxiliary material data sets are available at $\mathrm{ftp}$ //ftp.agu.org/apend/g1/ 2007gl029979. Other auxiliary material files are in the HTML. some other small components. Urban areas typically produce a very sharp contrast in time and size distribution between HOA and OOA, due to the more local nature of HOA and more regional nature of OOA, and to the differences in the diurnal cycles of these components [Zhang et al., 2005a; Volkamer et al., 2006].

[7] At almost all urban downwind and rural/remote sites, and in some urban locations, more than one type of OOA component is observed. We frequently identified a highly oxygenated OOA component that has a mass spectrum resembling that of fulvic acid (a model compound that has previously been proposed as representative for highly processed/oxidized organics present in the environment, sometimes known as humic-like substances [Fuzzi et al., 2001]), and a less oxygenated component whose spectrum is dominated by ions that are mainly associated with carbonyls and alcohols. The highly oxygenated OOA component is more prevalent at downwind sites influenced by urban transport, while the less oxygenated shows correlation to biogenic chamber OA at some locations. In a few of the datasets shown here, e.g., Houston (Canagaratna et al., manuscript in preparation, 2007) and Mexico City [Salcedo et al., 2006], biomass burning events account for a significant fraction of the total OOA. Biomass burning aerosols are estimated to make a major contribution to OA globally, although with a larger contribution further south from the midlatitude region covered here [Kanakidou et al., 2005]. Their effect at a specific ground site tends to be highly episodic depending on the proximity and intensity of major fires, and they can often be readily identified by tracers such as gas-phase acetonitrile and particle-phase levoglucosan and $\mathrm{K}^{+}$(e.g., Canagaratna et al., manuscript in preparation, 2007).

[8] The detailed quantitative apportionment of the various types of OOA to their sources using AMS spectra is a topic of intense current research. For clarity, here all of the OOA components are grouped together. In addition, typically only one HOA component was identified in each study, except for one case (TORCH I) where two HOA factors were extracted and grouped together. The mass spectra of three most representative OOA components are presented in the supporting material. Note that the total concentrations of the OOA components are robust and independent to the exact multiple component analysis method used [e.g., Ulbrich et al., 2006; Canagaratna et al., manuscript in preparation, 2007].

\section{Results and Discussion}

[9] OA comprises a major fraction $(18-70 \%$; average $=$ $45 \%$ ) of the non-refractory submicron particle mass at the various locations studied here (Figure 1), while sulfate (10$67 \%$; avg $=32 \%)$, nitrate $(1.2-28 \%$; avg $=10 \%)$, ammonium $(6.9-19 \%$; avg $=13 \%)$ and chloride $(<$ D.L. $-4.8 \%$; $\operatorname{avg}=0.6 \%)$ account for the rest of the particle mass. Figure 2 shows the results of the MCA analysis. Note that fewer datasets were collected during winter (see Table S1 in the auxiliary material), and a few (e.g., Beijing and Mexico City) were acquired in highly polluted megacities. The OA $(=\mathrm{HOA}+\mathrm{OOA})$ concentrations in Beijing and Mexico City are approximately $\sim 4-5$ times higher than the average OA concentration of the other 9 cities. 


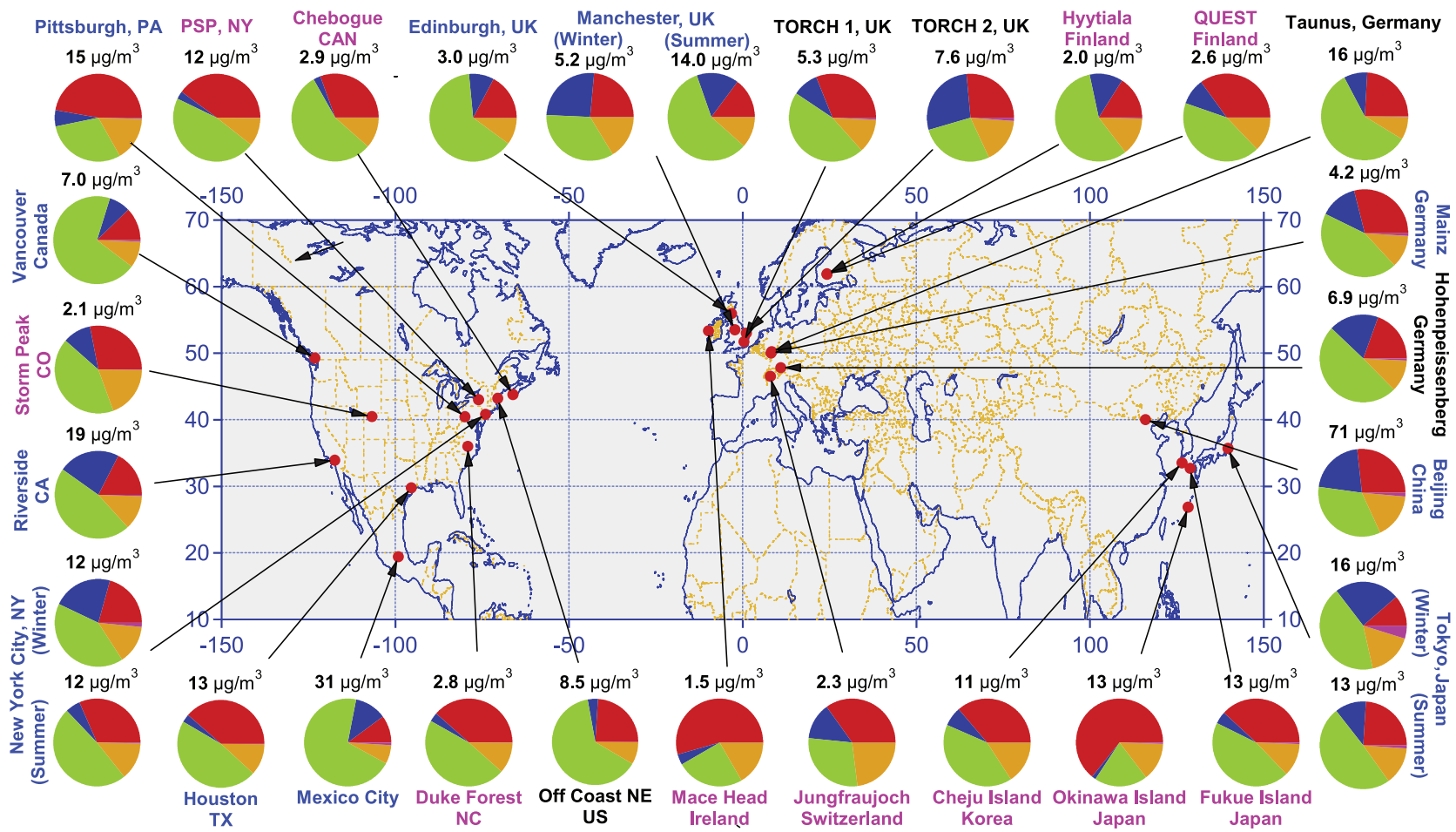

Figure 1. Location of the AMS datasets analyzed here (data shown in Table S1 in the auxiliary material). Colors for the study labels indicate the type of sampling location: urban areas (blue), $<100$ miles downwind of major cites (black), and rural/remote areas $>100$ miles downwind (pink). Pie charts show the average mass concentration and chemical composition: organics (green), sulfate (red), nitrate (blue), ammonium (orange), and chloride (purple), of NR-PM ${ }_{1}$.

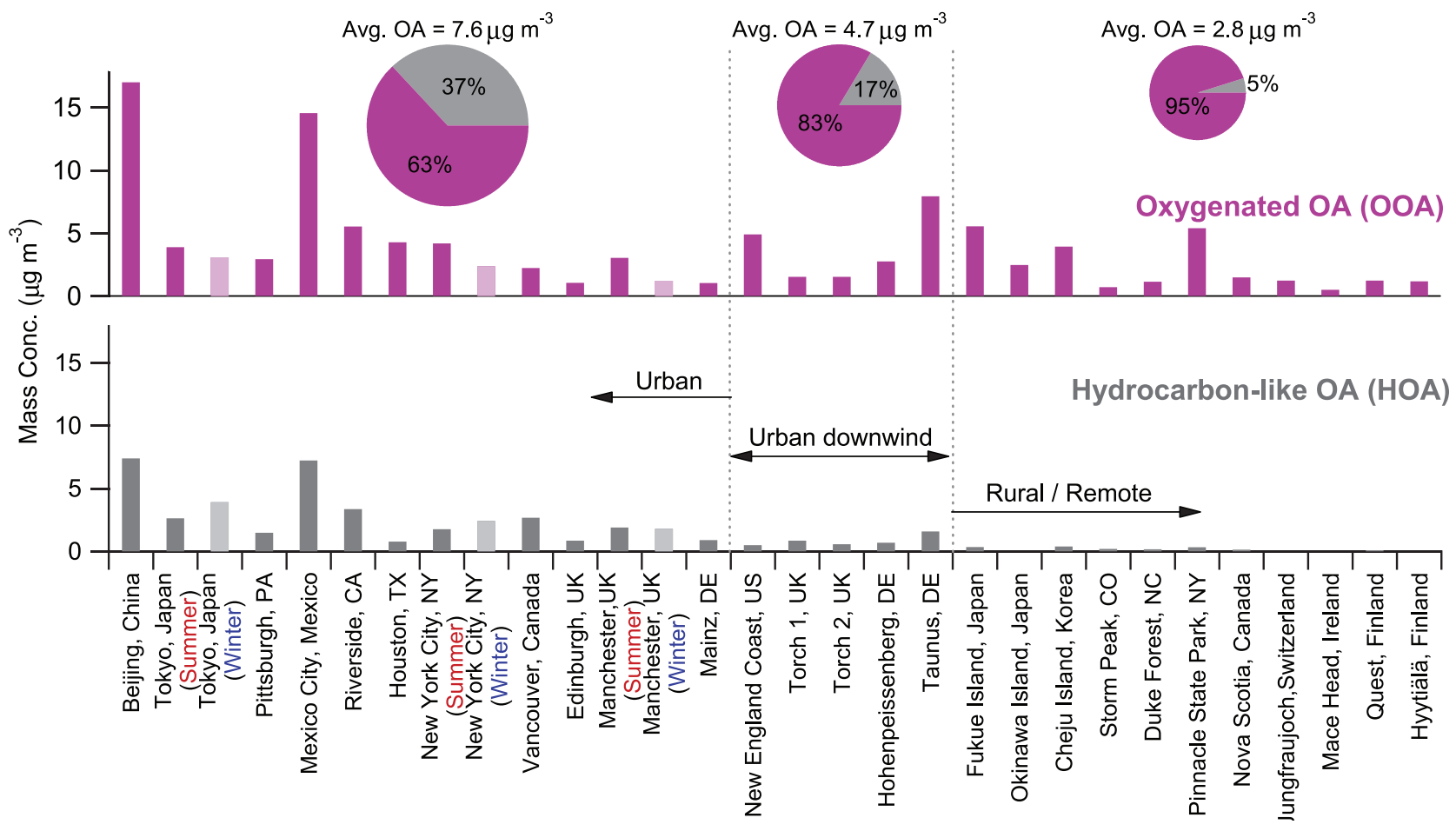

Figure 2. Average mass concentrations of HOA and total OOA (sum of several OOA types) at sites in the Northern Hemisphere (data shown in Table S1 in the auxiliary material). The winter data of the three urban winter/summer pairs are placed to the right of the summer data and are shown in a lighter shade. Within each category, sites are ordered from left to right as Asia, North America, and Europe. Areas of the pie charts are scaled by the average concentrations of total organics $(\mathrm{HOA}+\mathrm{OOA})$. 


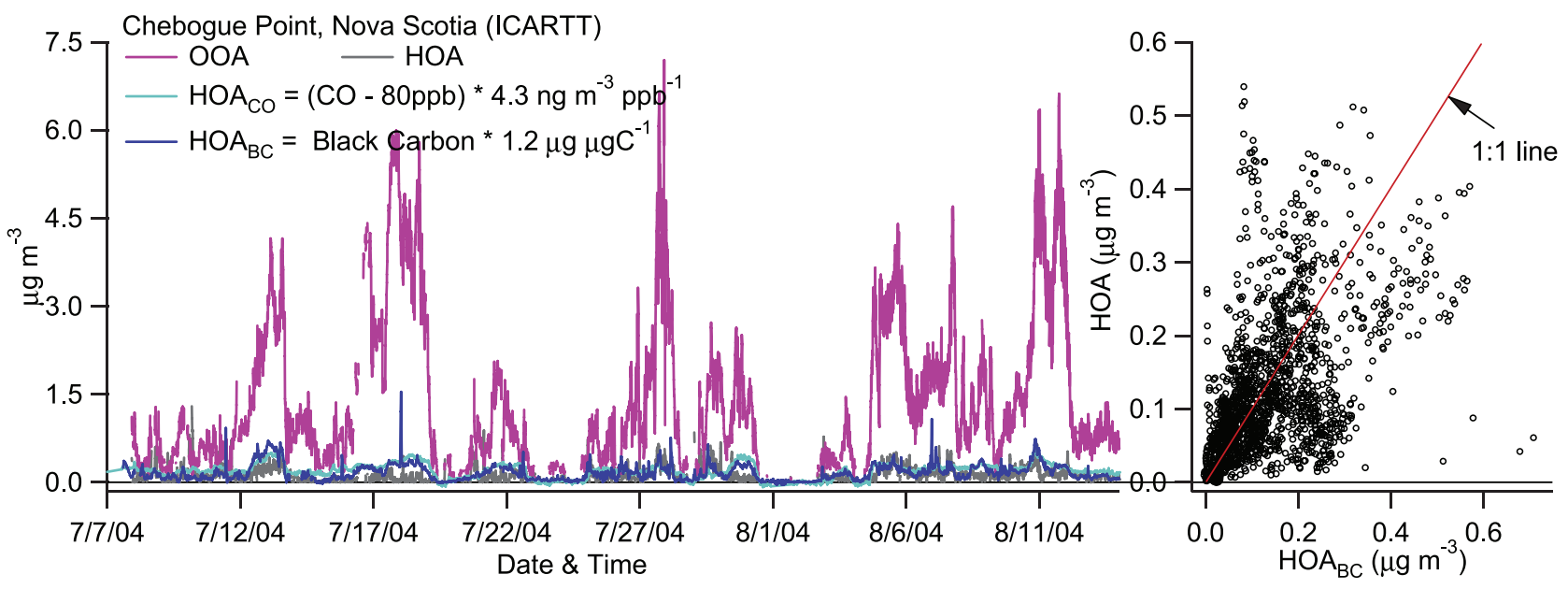

Figure 3. Time series of the mass concentrations of HOA and total OOA at Chebogue Point, Nova Scotia, in summer 2004 during ICARTT. Also shown are the time series of HOA estimated based on the average emission ratios of HOA/CO

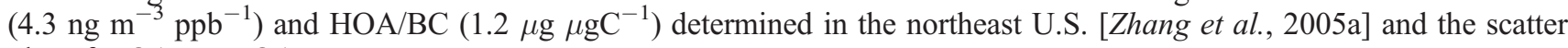
plot of $\mathrm{HOA}$ vs. $\mathrm{HOA}_{\mathrm{BC}}$.

[10] Several patterns regarding HOA and OOA distributions appear in Figure 2: (1) the average mass concentrations of OOA are generally of the same order in urban, downwind, and rural/remote areas; (2) urban OOA concentrations are highest in two polluted and photochemically active megacities (Beijing and Mexico City); (3) the fraction of OOA is comparable to but higher than that of HOA in the majority of urban areas studied; (4) the urban downwind and especially rural/remote locations are almost completely dominated by OOA; (5) HOA levels are similar in all the cities studied, except in Mexico City and Beijing; and (6) the HOA concentrations are lower in urban downwind and very small in rural/remote areas. In general, cities act as sources of HOA that quickly loses importance downwind, while OOA maintains similar or higher levels in the urban and downwind regions and its contribution to total $\mathrm{OA}$ generally increases further downwind.

[11] The results of the MCA analysis for winter/summer city pairs are highlighted in Figure 2 using a lighter shade for the winter data. In all three cities, OOA is larger in the summer, which is consistent with increased emissions of SOA precursors and enhanced SOA formation rates by increased solar radiation. Conversely, HOA is larger in the winter, which is consistent with increased emissions from heating, reduced HOA evaporation, and reduced dilution in winter, due to the relatively suppressed vertical mixing associated with lower surface temperatures.

[12] The possible sources for the OOA observed in these studies include SOA (from either anthropogenic or biogenic precursors), the oxidation of HOA, and/or BBOA. The relatively low variability in OOA levels across our studies and analyses based on BB tracers (e.g., AMS m/z 60, acetonitrile, and potassium) are consistent with the conclusion that biomass burning events, which are usually episodic, are not a major contributor to OOA in most of the studies presented here, although they do play an important role in Mexico City [Salcedo et al., 2006] and Houston (Canagaratna et al., manuscript in preparation, 2007) during some time periods. There is strong evidence linking OOA to SOA for many of the studies summarized here in or downwind of urban areas: Pittsburgh [Zhang et al., 2005a], Mexico City [Volkamer et al., 2006], Tokyo [Takegawa et al., 2006], downwind of London [Johnson et al., 2006], and downwind of the US East Coast [de Gouw et al., 2005]. Other studies have also found a large contribution of SOA in the free troposphere downwind of East Asia [Heald et al., 2005] where the OA was completely dominated by OOA [Bahreini et al., 2003], which suggest that SOA is also an important contributor to the OOA observed in the AMS studies presented here over the western Pacific Ocean.

[13] An important observation is the very limited importance of urban/fossil fuel combustion HOA as a contributor to organic aerosol mass on regional scales. Although POA compounds can be oxidized in the particle-phase [e.g., Morris et al., 2002] and could in principle become OOA, the time scale of this oxidation is at least several days [Schauer et al., 1996; Molina et al., 2004; Zhang et al., 2005a; Volkamer et al., 2006]. However, the lack of a significant contribution of HOA to urban downwind and rural/remote locations can be largely explained by atmospheric dilution of relatively high urban concentrations of HOA, which occur over a small footprint, into an OOAdominated regional environment with a much larger atmospheric volume.

[14] Figure 3 supports this point using data collected at the Chebogue Point, Nova Scotia field site during the 2004 ICARTT campaign, where BBOA is known to make a minor contribution based on low acetonitrile [Holzinger et al., 2007]. The concentration of HOA derived from the MCA analysis is similar to or smaller than the POA that would be predicted using either $\mathrm{CO}$ or black carbon $(\mathrm{BC})$ as tracers. The Pearson's R between HOA and BC is $\sim 0.5$. Lower measured than predicted HOA during some periods indicates partial oxidation of this component and/or possibly additional evaporation of HOA upon dilution, although some of the deviations may be due to the difficulty of precisely retrieving a small fraction of HOA from spectra dominated by much larger fractions of OOA. Nevertheless, oxygenated OA accounts for almost all of the total OA 
(average $=91 \%$; Figure 2 and Table S2) and is much larger than the measured HOA or predicted POA, consistent with a previous study in this area [de Gouw et al., 2005]. Note that even though the contribution of HOA to particle mass in urban downwind regions is very small, the contribution of primary emissions to particle number concentrations (onto which secondary species condense) can still be very important [e.g., Spracklen et al., 2006]. The fact that the OOA concentration decreases little from urban to downwind regions as the air mass is diluted is indicative of an extended SOA source (either from urban emissions or from regional biogenic emissions), consistent with recent studies [Goldstein and Galbally, 2007; Robinson et al., 2007], although large amounts of OOA can also be produced in the urban environment [Volkamer et al., 2006]. Finally, Robinson et al. [2007] reported that the semivolatile and intermediate volatility primary emissions (SVOCs and IVOCs respectively), which are co-emitted with $\mathrm{POA} / \mathrm{HOA}$ but in about an order of magnitude higher concentration, may be a significant source of SOA/OOA over regional scales. Our results concerning the limited contribution of HOA to OA mass refer to the HOA present in the particlephase in the urban background [e.g., Zhang et al., 2005a] when evaporation of SVOCs has already taken place. Our results are potentially consistent with, but are not sufficient to prove (or disprove), a large contribution to regional OOA by anthropogenic SVOC and IVOC oxidation.

\section{Implications for Global Models}

[15] A global distribution of OA in time, space, stateof-mixing, particle size, and water-uptake and optical properties, which can only be estimated from global models, is needed to evaluate the effects of aerosols on climate. It is of great interest to compare our results for the composition and distribution of OA with the current state-of-the-art global modeling. A recent study [Textor et al., 2006] from the AeroCom initiative, which compares aerosol simulation across global models, reports the following features for the representation of organic aerosols in 16 models: (1) most OA in the models is POA; (2) most models age the POA by oxidation only with a fixed time-scale of $1-$ 2 days; (3) SOA is explicitly simulated in only 1 out of 16 models; (4) most models include biogenic SOA in the POA emissions; (5) anthropogenic SOA is neglected by most models; and (6) in some models all SOA is completely neglected.

[16] Comparing these model features with the measurement results from the previous section, it appears that the importance of POA with respect to aerosol mass is overestimated while SOA is underestimated by most models. The dominant mechanism of OA evolution in the atmosphere is likely condensation of inorganic species and SOA onto the POA, rather than oxidation of POA [Zhang et al., 2005a; Volkamer et al., 2006; Petters et al., 2006], and the time scale is determined by the availability of precursors and atmospheric oxidants, rather than being a fixed value. SOA is modeled based on parameterized results from chamber studies conducted under unrepresentative conditions. Finally, the inclusion of SOA as a fraction of POA emissions may produce biases in the spatial, temporal, and mixing state distribution of POA and SOA and in the water uptake properties of simulated SOA. However, before global models can move towards a more explicit representation of SOA, new SOA process models built on a sound understanding of the underlying physical and chemical processes need to be developed.

\section{Conclusions}

[17] Analyses of 37 field studies in urban and anthropogenically influenced rural/remote areas indicate the ubiquity and dominance of oxygenated species in organic aerosols, of which a major fraction is likely to be secondary in nature. While hydrocarbon-like organic aerosol (HOA) makes a significant contribution to aerosol mass in urban boundary layers, its importance in rural/remote areas is small compared to the oxygenated fraction due to dilution. Atmospheric oxidation of HOA which may be occurring, cannot result in enough mass to explain even a minor fraction of the observed OOA. In light of our results, the representation of OA in global models appears to have an overemphasis on POA and a lack of explicit representation of SOA. This likely leads to significant biases in the amount as well as the spatial and temporal concentrations and properties of OA.

[18] Acknowledgments. This work was supported by EPA RD832161010, SUNY-Albany Startup funds, NSF-ATM0449815, and NASA-NNG04GA67G. The support of individual studies is given in the auxiliary material. This work has not been subjected to agency review and does not necessarily reflect the views of the agencies. We thank the AMS Community for helpful discussions.

\section{References}

Alfarra, M. R., et al. (2006), A mass spectrometric study of secondary organic aerosols formed from the photooxidation of anthropogenic and biogenic precursors in a reaction chamber, Atmos. Chem. Phys., 6, 5279-5293.

Allan, J. D., et al. (2004), A generalised method for the extraction of chemically resolved mass spectra from AMS data, J. Aerosol Sci., 35(7), 909-922.

Bahreini, R., J. L. Jimenez, J. Wang, R. C. Flagan, J. H. Seinfeld, J. T. Jayne, and D. R. Worsnop (2003), Aircraft-based aerosol size and composition measurements during ACE-Asia using an Aerodyne aerosol mass spectrometer, J. Geophys. Res., 108(D23), 8645, doi:10.1029/ 2002JD003226.

Bahreini, R., et al. (2005), Measurements of SOA from oxidation of cycloalkenes, terpenes, and m-xylene using an AMS, Environ. Sci. Technol., 39, 5674-5688

Canagaratna, M. R., et al. (2007), Chemical and microphysical characterization of ambient aerosols with the AMS, Mass Spectrom. Rev., 26, $185-222$.

de Gouw, J. A., et al. (2005), Budget of organic carbon in a polluted atmosphere: Results from the New England Air Quality Study in 2002, J. Geophys. Res., 110, D16305, doi:10.1029/2004JD005623.

Fuzzi, S., S. Decesari, M. C. Facchini, E. Matta, M. Mircea, and E. Tagliavini (2001), A simplified model of the water soluble organic component of atmospheric aerosols, Geophys. Res. Lett., 28(21), 4079-4082.

Goldstein, A., and I. Galbally (2007), Known and unexplored organic constituents in the Earth's atmosphere, Environ. Sci. Technol., 40(5), $1514-1521$.

Heald, C. L., D. J. Jacob, R. J. Park, L. M. Russell, B. J. Huebert, J. H. Seinfeld, H. Liao, and R. J. Weber (2005), A large organic aerosol source in the free troposphere missing from current models, Geophys. Res. Lett., 32, L18809, doi:10.1029/2005GL023831.

Holzinger, R., D. B. Millet, B. Williams, A. Lee, N. Kreisberg, S. V. Hering, J. Jimenez, J. D. Allan, D. R. Worsnop, and A. H. Goldstein (2007), Emission, oxidation, and secondary organic aerosol formation of volatile organic compounds as observed at Chebogue Point, Nova Scotia, J. Geophys. Res., 112, D10S24, doi:10.1029/2006JD007599.

Jayne, J. T., et al. (2000), Development of an AMS for size and composition analysis of submicron particles, Aerosol Sci. Technol., 33, 49-70.

Jimenez, J. L., et al. (2003), Ambient aerosol sampling using the Aerodyne Aerosol Mass Spectrometer, J. Geophys. Res., 108(D7), 8425, doi:10.1029/2001JD001213. 
Johnson, D., et al. (2006), Simulating regional scale SOA formation during the TORCH 2003 campaign in the southern UK, Atmos. Chem. Phys., 6, 403-418.

Kanakidou, M., et al. (2005), Organic aerosol and global climate modelling: A review, Atmos. Chem. Phys., 5, 1053-1123.

Kondo, Y., Y. Miyazaki, N. Takegawa, T. Miyakawa, R. J. Weber, J. L. Jimenez, Q. Zhang, and D. R. Worsnop (2007), Oxygenated and watersoluble organic aerosols in Tokyo, J. Geophys. Res., 112, D01203, doi:10.1029/2006JD007056.

Lanz, V. A., et al. (2007), Source apportionment of submicron organic aerosols at an urban site by factor analytical modelling of aerosol mass spectra, Atmos. Chem. Phys., 7, 1503-1522.

Molina, M. J., A. V. Ivanov, S. Trakhtenberg, and L. T. Molina (2004), Atmospheric evolution of organic aerosol, Geophys. Res. Lett., 31, L22104, doi:10.1029/2004GL020910.

Morris, J. W., P. Davidovits, J. T. Jayne, J. L. Jimenez, Q. Shi, C. E. Kolb D. R. Worsnop, W. S. Barney, and G. Cass (2002), Kinetics of submicron oleic acid aerosols with ozone: A novel aerosol mass spectrometric technique, Geophys. Res. Lett., 29(9), 1357, doi:10.1029/2002GL014692.

Petters, M. D., A. J. Prenni, S. M. Kreidenweis, P. J. DeMott, A. Matsunaga, Y. B. Lim, and P. J. Ziemann (2006), Chemical aging and the hydrophobic-to-hydrophilic conversion of carbonaceous aerosol, Geophys. Res. Lett., 33, L24806, doi:10.1029/2006GL027249.

Robinson, A. L., N. M. Donahue, M. K. Shrivastava, E. A. Weitkamp, A. M. Sage, A. P. Grieshop, T. E. Lane, J. R. Pierce, and S. N. Pandis (2007), Rethinking organic aerosols: Semivolatile emissions and photochemical aging, Science, 315, 1259-1262, doi:10.1126/science.1133061.

Russell, L. M. (2003), Aerosol organic-mass-to-organic-carbon ratio measurements, Environ. Sci. Technol., 37(13), 2982-2987.

Salcedo, D., et al. (2006), Characterization of ambient aerosols in Mexico City during the MCMA-2003 campaign with AMS: Results from the CENICA Supersite, Atmos. Chem. Phys., 6, 925-946.

Schauer, J. J., W. F. Rogge, L. M. Hildemann, M. A. Mazurek, and G. R. Cass (1996), Source apportionment of airborne particulate matter using organic compounds as tracers, Atmos. Environ., 30, 3837-3855.

Spracklen, D. V., et al. (2006), The contribution of boundary layer nucleation events to total particle concentrations on regional and global scales, Atmos. Chem. Phys., 6, 5631-5648.

Sullivan, A. P., R. J. Weber, A. L. Clements, J. R. Turner, M. S. Bae, and J. J. Schauer (2004), A method for on-line measurement of water-soluble organic carbon in ambient aerosol particles: Results from an urban site, Geophys. Res. Lett., 31, L13105, doi:10.1029/2004GL019681.

Takegawa, N., T. Miyakawa, Y. Kondo, J. L. Jimenez, Q. Zhang, D. R. Worsnop, and M. Fukuda (2006), Seasonal and diurnal variations of submicron organic aerosols in Tokyo observed using the Aerodyne aerosol mass spectrometer, J. Geophys. Res., 111, D11206, doi:10.1029/ 2005JD006515.

Textor, C., et al. (2006), Analysis and quantification of the diversities of aerosol life cycles within AeroCom, Atmos. Chem. Phys., 6, 1777-1813.

Turpin, B., P. Saxena, and E. Andrews (2000), Measuring and simulating particulate organics in the atmosphere: Problems and prospects, Atmos. Environ., 34, 2983-3013.

Ulbrich, I., et al. (2006), Source apportionment of AMS data in Pittsburgh, Mexico City, and Houston by PMF, Eos Trans. AGU, 87(52), Fall Meet Suppl., Abstract A23C-0980.
Volkamer, R., J. L. Jimenez, F. San Martini, K. Dzepina, Q. Zhang, D. Salcedo, L. T. Molina, D. R. Worsnop, and M. J. Molina (2006), Secondary organic aerosol formation from anthropogenic air pollution: Rapid and higher than expected, Geophys. Res. Lett., 33, L17811, doi:10.1029/2006GL026899.

Zhang, Q., et al. (2005a), Hydrocarbon-like and oxygenated organic aerosols in Pittsburgh: Insights into sources and processes of organic aerosols, Atmos. Chem. Phys, 5, 3289-3311.

Zhang, Q., et al. (2005b), Deconvolution and quantification of hydrocarbon-like and oxygenated organic aerosols based on Aerosol Mass Spectrometry, Environ. Sci. Technol., 39, 4938-4952.

Zhang, Q., et al. (2006), Component analysis of organic aerosols in urban, rural, and remote site atmospheres based on AMS, paper presented at 7 th International Aerosol Conference, Am. Assoc. for Aerosol Res., St. Paul, Minn., 10-15 Sept.

M. R. Alfarra, Laboratory for Atmospheric Chemistry, Paul Scherrer Institute, OFLA/005, CH-5232 Villigen PSI, Switzerland.

J. D. Allan, K. Bower, H. Coe, and P. Williams, School of Earth, Atmospheric and Environmental Science, University of Manchester, Main Building, Sackville Street, Manchester M60 1QD, UK.

R. Bahreini and A. M. Middlebrook, Chemical Sciences Division, NOAA Earth System Research Laboratory, 325 Broadway, Boulder, CO 80303, USA.

S. Borrmann, F. Drewnick, and J. Schneider, Department of Particle Chemistry, Max Planck Institute for Chemistry, Mainz D-55128, Germany.

M. R. Canagaratna, J. T. Jayne, T. Onasch, and D. R. Worsnop, Aerodyne Research Inc., 45 Manning Road, Billerica, MA 01821-3976, USA.

L. Cottrell and R. J. Griffin, Climate Change Research Center, University of New Hampshire, Durham, NH 03824, USA.

P. F. DeCarlo, K. Docherty, E. Dunlea, K. Dzepina, J. L. Jimenez, and I. Ulbrich, Cooperative Institute of Research in Environment Sciences and Department of Chemistry and Biochemistry, University of Colorado, Boulder, CO 80309-0216, USA. (jose.jimenez@colorado.edu)

K. Demerjian, Y. L. Sun, S. Weimer, and Q. Zhang, Atmospheric Sciences Research Center, University at Albany, State University of New York, 251 Fuller Road, Albany, NY 12203, USA. (qz@asrc.cestm.albany.edu)

S. Hatakeyama, T. Miyoshi, and A. Takami, Chemical Reaction Section, Atmospheric Environment Division, National Institute for Environmental Studies, Onogawa 16-2, Tsukuba, Ibaraki 305-8506, Japan.

Y. Kondo and N. Takegawa, Research Center for Advanced Science and Technology, University of Tokyo, 4-6-1 Komaba, Meguro-ku, Tokyo 1538904, Japan.

J. Rautiainen, Department of Physics, University of Kuopio, P.O. Box 1627, FI-70211 Kuopio, Finland.

D. Salcedo, Centro de Investigaciones Quimicas, Universidad Autónoma del Estado de Morelos, Avenida Universidad 1001, Cuernavaca Morelos 62209, México.

A. Shimono, Sanyu Plant Service Co., Ltd., Hashimotodai 1-8-21, Sagamihara, Kanagawa 229-1132, Japan.

J. Y. Sun and Y. M. Zhang, Center for Atmosphere Watch and Services, Chinese Academy of Meteorological Sciences, China Meteorological Administration, Beijing 100081, China. 